\title{
Intelligent Construction, Operation, and Maintenance of a Large Wastewater-Treatment Plant Based on BIM
}

\author{
Jiu-Lin Li, ${ }^{1,2}$ Li-Min Chen, ${ }^{3}$ and Hao Xu $\mathbb{D}^{2}$ \\ ${ }^{1}$ Tsinghua University, Beijing 100084, China \\ ${ }^{2}$ Beijing Urban Construction Group Co.,Ltd., Beijing 100088, China \\ ${ }^{3}$ National Speed Skating Oval Co.Ltd., Beijing 100101, China \\ Correspondence should be addressed to Hao Xu; 804713698@qq.com
}

Received 11 November 2020; Accepted 27 April 2021; Published 10 May 2021

Academic Editor: Hui Yao

Copyright (C) 2021 Jiu-Lin Li et al. This is an open access article distributed under the Creative Commons Attribution License, which permits unrestricted use, distribution, and reproduction in any medium, provided the original work is properly cited.

Building information modeling (BIM) is a data-based tool for engineering, design, and building management, which is used to parameterize and model various types of information. This information may then be shared and introduced throughout the building life-cycle phases (planning, design, construction and operation, and maintenance (O\&M)). Therefore, BIM allows engineers to correctly understand and efficiently respond to varying types of building information as well as serves as a foundation for cooperation between the design and construction teams. Hence, BIM plays an important role in increasing productivity, minimizing costs, and shortening construction times. In this article, we present a case example where BIM was used for intelligent construction of a large wastewater-treatment plant (WTP). The process involved intelligent design and simulation techniques, management and simulation of construction works, digital delivery solutions, BIM-based Internet of things O\&M, and environmental monitoring. BIM was used to digitalize the construction, delivery, and O\&M processes of the WTP. According to this case example, we also offer suggestions on how deep learning and intelligent control techniques can be used to enhance intelligent O\&M in WTPs.

\section{Introduction}

As a traditional industry, the construction industry has an important contribution to the development of the world economy. According to the statistical data of Statista and Global Infrastructure Outlook, the scale of the world's construction industry has grown from USD 9.5 trillion in 2014 to USD 11.4 trillion in 2019, and in the next 20 years, global infrastructure investment will reach USD 94 trillion. However, the problems caused by the development of the construction industry have become increasingly prominent, such as high resource consumption, high pollution emissions, and low quality and efficiency (Q\&E). The buildings and construction sector accounted for $36 \%$ of final energy use and $39 \%$ of energy and process-related carbon dioxide $\left(\mathrm{CO}_{2}\right)$ emissions in $2018,11 \%$ of which resulted from manufacturing building materials and products such as steel, cement, and glass. As a raw material, building materials consume almost $60 \%$ of the raw materials in the lithosphere, and a large amount of energy consumption is also caused during their extraction, process, and production [1-5]. At the same time, the construction industry occupies $60 \%$ of the main agricultural land and $70 \%$ of the wood and the construction process consumes $12-16 \%$ of global water resources and produces about $45 \%$ to $65 \%$ of the global landfill waste components. More and more evidences show that the construction industry is one of the main factors causing the global environmental deterioration, which makes the green sustainable development of construction industry more widely recognized [6-10]. Information application is an important means for the construction industry to transform its development mode, improve Q\&E, save energy, and reduce emissions. Informatization construction refers to the system method that integrates information technology, tool software, management system, and so on and provides technical support for the project construction team from the 
whole construction process of planning, design, production, construction, and operation. Due to the transferability of information data in each phase, the application of information technology is only used in some links in the previous, which is a decentralized and fragmented application. With the development of BIM, Internet of things (IoT), mobile communication, and other technologies, information construction has gradually been equipped with the conditions throughout a building's life cycle. It is an important part of the development strategy of the construction industry. Building information modelling (BIM) is one of the crucial topics in the informatization of the construction industry, which is the basis for intelligent construction. This paper presents the influence of BIM benefits on the intelligent construction, operation, and maintenance of a large WTP. The manuscript is organized as follows. Section 2 illustrates the literature background and research review. Section 3 introduces the methodology. Section 4 shows how the case study for a large WTP is. Finally, Section 5 summarizes the conclusions and sets the goals for future developments.

This paper introduces the application of BIM technology in large urban infrastructure projects. By analysing a case example where BIM was used for intelligent construction of a large wastewater-treatment plant, the effects of BIM technology on the design, construction, and O\&M processes of engineering were carefully studied, and thus, the intelligent construction technology system based on BIM technology is developed. This study could also be a reference for other intelligent construction and scientific management and control of large-scale public service facilities.

\section{Background}

As a traditional industry, the construction industry has been a major driver of economic growth. However, it is also a classic example of "resource intensive, polluting, inefficient, and low-quality" extensive development industry, which has hampered its rapid and sustainable development. The construction industry shall thus become much more efficient, competitive, and beneficent and will simultaneously create social, economic, and environmental benefits. BIM is a new approach introduced in construction projects to manage building design, construction, and O\&M data in digital form throughout a building's life cycle and an approach that provides the exchange and interoperability of information among the stakeholders [11, 12]. BIM is utilized not just as a model but also as a suitable platform for coworking and information transferring between participants in all processes of the project and ensures that no information faults will occur when information is transferred from one stage to another. Its great advantages in deepening design, saving construction time, reducing cost, and improving Q\&E have driven construction players to adopt it and increasingly implement it in all stages of construction [13-17]. It is a multidimensional model information integration technology which realizes the digital bearer and visual expression of physical characteristics and functional information of construction projects [18]. Hence, BIM provides the foundation for the virtual construction and refined management of engineering projects and at the same time provides technical guarantee for improving Q\&E and industrial upgrading [19].

\section{Methodology}

3.1. Intelligent Design and Simulation Technologies. During the design, building information models were used to provide intuitive illustrations of the underground structures. The BIM models were then exported into Revit, Ecotect, Phoenics, CadnaA, and Pathfinder to perform specialized simulations of the key nodes to help optimize its design. The BIM model that was developed in the design phase was then introduced to the construction and O\&M phases, thus creating a foundation for the use of BIM throughout in the WTP life cycle. The BioWin simulator was used to simulate and optimize the WTP processes and provide technical support for the O\&M processes. First of all, we need to calculate and determine the size and operation parameters of each treatment structure by using the traditional design method according to the design of the water quality and water treatment process. Then, the design parameters are input into the BioWin application and transformed into the structures and parameters in the model. Based on this, the process flow is established on the model, and the process design is optimized through the comparison and selection of different design schemes. The use of BIM and BioWin in the design phase sets the stage for the creation of an intelligent WTP.

3.2. Construction Management and Simulation Technologies. By combining the BIM models with the 3D geographic information systems (3D-GISs) and IoT technology, we independently built a 3D IoT construction management platform to ensure the safety, progress, quality, and cost efficiency of the construction site, which effectively improved our ability to precisely manage this construction project using information technologies. In addition, a simulation analysis was performed on the construction process using the "interval casting method" to ensure that the construction would be smoothly implemented in WTP. Before construction, ANSYS software is used to simulate the whole process of construction so as to determine the sequence, spacing, and size of the interval casting method. During construction, permanent temperature and stress sensors were installed in the HWTP structure to collect stress and temperature data and to monitor structural changes in the concrete. Finally, the interval casting method was carried out orderly according to the data comprehensive of finite-element analysis and real-time monitoring.

3.3. Digital Delivery and O\&M Technologies. We established a BIM delivery standard by developing an industry foundation classes (IFC) interface and defining a BIM O\&M coding system, which effectively integrated the engineering data that were scattered across different life-cycle phases and specializations and established crosslinks among these data. The BIM delivery data were thus integrated to develop a 
complete O\&M model (Table 1), which will serve as O\&M management information source in the future. In addition, a hierarchical O\&M information system and a corresponding set of modeling methods were proposed for the research object based on its intrinsic features. This information system provided natural groupings for the subinformation models (e.g., GIS and BIM models) of the WTP, which varied in scale and scope. Local data augmentation, model scale conversions, and information fusion were performed to provide a low-level support for the construction of this hierarchical information system. In addition, a cloud infrastructure was used to enable integration and sharing of big data from the WTP O\&M processes (Figure 1).

\section{Case Study}

4.1. Case Study Description. As a super-large city, Beijing is a severely water-scarce city. With the rapid development of society and economy, the contradiction between supply and demand of water resources has become prominent. In order to improve the level of sewage treatment and utilization of reclaimed water, Beijing has formulated the "Three-year Action Plan for Accelerating the Construction of Wastewater Treatment and Reclaimed Water Utilization Facilities in Beijing (2013-2015)," which promotes the construction of reclaimed water plant. Wastewater-treatment plants (WTPs) are typically constructed aboveground or underground. The former type is more common. Aboveground WTPs are cheaper to construct and operate than their underground counterparts, and operating and maintaining them are relatively straightforward. However, the construction of aboveground WTPs inevitably results in land waste, environmental pollution, and devaluation of its surrounding lands. By comparison, underground WTPs take up very little space, produce lesser noise, exert a lower environmental effect, help conserve land resources, and are more aesthetically pleasing (see Table 2). With the rapid urbanization of China and the growing environmental demands of its residents, underground WTPs have become the preferred choice for urban wastewater treatment in land-scarce areas whenever local economic conditions permit. This preference may be attributed to the sealed nature of underground WTPs and their ability to maintain harmony with their surrounding areas. The Huaifang Water Treatment Plant (HWTP) is currently the largest underground WTP in Asia. Most of its water treatment processes are performed underground, and a $15.62 \mathrm{hm}^{2}$ wetland park lies on its surface, making it a place for rest and relaxation of nearby residents. HWTP represents a future direction of WTP developments in China.

\subsection{Case Study Implementation}

\subsubsection{Intelligent BIM-Based Construction of HWTP}

(1) Intelligent BIM-Based Design of HWTP. The BIM models played an important role in the optimization of the HWTP design because they provided an intuitive display of the complex spatial relationships of its underground structures and enabled specialized simulations of its key nodes by exporting the models into simulation software. The design process was mainly performed using Autodesk Revit, aided by supplementary programs such as Civil3D and Navisworks. The BIM model was employed in the computational analyses and simulation programs to perform supplementary computations and simulation analyses for the survey design, comparison of design alternatives, design optimization, and construction collaboration phases. The performed simulations and analyses including site analysis, daylight visualization, visibility analysis, evacuation simulations, ventilation and deodorization simulations, noise simulations, interference checking, and sheet creation. These processes enhanced the level of precision and refinement of the HWTP design and created a basic model for its construction and O\&M processes.

In a complex project such as HWTP, BIM is very important for such tasks as three-dimensional (3D) pipeline design. According to the interference-checking functionality of the BIM technique, Revit modeling was used to visualize the spatial relationships among the pipelines and perform interference checking. The design of the pipelines was then modified according to the interference-checking report to create a rational plan for the HWTP 3D spaces (Figure 2).

(2) BioWin Simulation of Wastewater-Treatment Processes. During the design phase of a WTP, the BioWin simulator can be used to perform steady-state simulations of a process flow solution so that appropriate modifications can be made according to the simulation results. This process allows the construction and operation costs to be reduced without any detriment to the output water quality. In HWTP, dynamic simulations can be performed according to the actual inflow water-quality levels and current state of its water treatment facilities. The results of these simulations can then be used to formulate technical solutions to optimize its operations and develop a rational basis for modifications to improve its efficiency.

In the present work, traditional methods were first used to determine the dimensions and operating parameters of the HWTP structures based on the designed inflow waterquality levels and preliminary HWTP process. The design parameters were then input into the BioWin simulator and converted into buildings and parameters using a BioWin model, which was then used to construct the process flows for the water treatment process. After the inflow water quality was determined, simulations were performed on several biological tank designs. Each design had a hydraulic retention time of $17.8 \mathrm{~h}$ and varying partitions for its anaerobic, anoxic, and aerobic zones (Figure 3 ). The effluent water qualities in each design were then compared, and the best design was selected for the biological tank.

(3) IoT-Based Comprehensive Construction Management. According to the BIM, cloud computing, and IoT technology, we integrated engineering-information modeling, building-performance analysis, detailed design, factory processing, high-precision measurements, structural monitoring, five-dimensional construction management, and O\&M management in the BIM application and thus established a BIM- and IoT-based construction platform for 
TABle 1: Types of information in the O\&M model of the HWTP.

\begin{tabular}{|c|c|c|c|c|}
\hline No. & Type & $\begin{array}{c}\text { Size/ } \\
\text { number }\end{array}$ & Format & Description \\
\hline 1 & Building structure model & $1.4 \mathrm{~GB}$ & rvt & $\begin{array}{c}\text { Includes the structural models of all buildings in the water and production } \\
\text { zones }\end{array}$ \\
\hline 2 & $\begin{array}{l}\text { Mechanical and electrical } \\
\text { equipment models }\end{array}$ & $1.6 \mathrm{~GB}$ & rvt, dwf & $\begin{array}{c}\text { Include the main equipment in the water zones and some in the pipeline } \\
\text { models }\end{array}$ \\
\hline 3 & Drawings & 63 & dwg & $\begin{array}{l}\text { Include the blueprints of the coarse screen, membrane screen, biological } \\
\text { tank, and membrane bioreactor as well as the treatment process diagrams }\end{array}$ \\
\hline 4 & Photographs & 41 & jpg & $\begin{array}{c}\text { Photographs of some of the wastewater-treatment equipment in the water } \\
\text { zones }\end{array}$ \\
\hline 5 & Electronic files & 56 & doc, pdf & Process descriptions and equipment manuals \\
\hline 6 & Equipment parameter files & 111 types & xls & $\begin{array}{l}\text { Parameter tables of all equipment, including the coarse screen, membrane } \\
\text { screen, biological tank, and membrane bioreactor }\end{array}$ \\
\hline 7 & Monitoring data & - & $\begin{array}{l}\text { Provided by } \\
\text { OPC }\end{array}$ & $\begin{array}{c}\text { Flow measurement and water-quality monitoring of the inlet and outlet } \\
\text { (effluent), water-level monitoring in all water zones, and data from the } \\
\text { membrane screen toxic-gas warning system }\end{array}$ \\
\hline
\end{tabular}

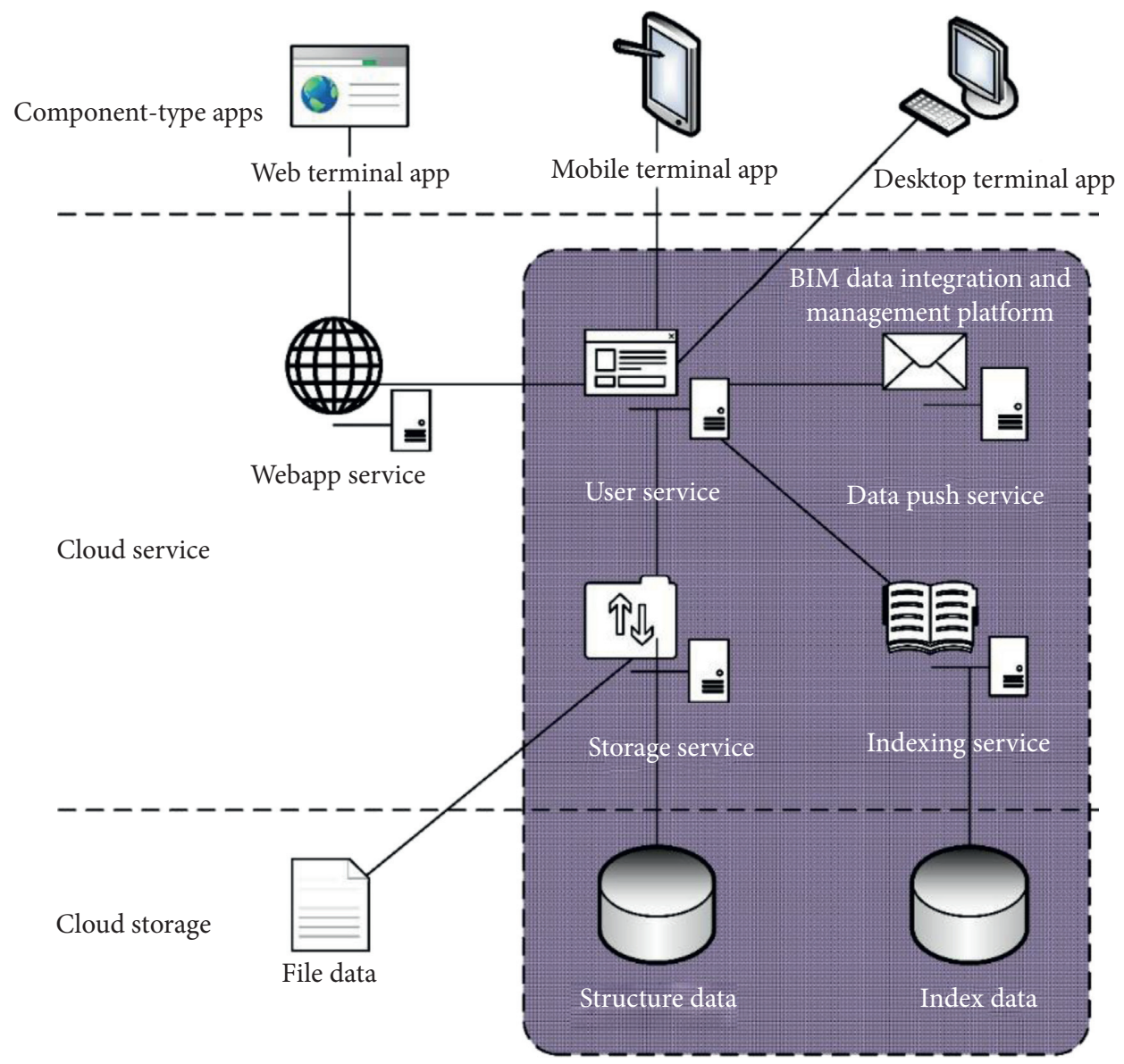

Figure 1: Cloud-based BIM O\&M database.

"intelligent WTPs." Through the 3D-GIS, BIM, and IoT technologies, this platform can be used to manage on-site personnel, machinery, and materials.

This platform was implemented using website and mobile application (Figure 4) terminals, and it included video monitoring, personnel management, material management, and automated monitoring modules. This system effectively centralized much of the site-management data, allowed managers to operate from mobile offices, enabled real-time project management, and facilitated storage and querying of historical data. Further, the platform provided up-to-date and accurate data for the O\&M processes. Therefore, this platform is a valuable addition to the project.

(4) Implementation of the "Interval Casting Method" Based on Computational Simulations. This study is the first one to 
TABLE 2: Comparison between conventional aboveground and underground WTPs.

\begin{tabular}{|c|c|}
\hline Aspect & Conventional aboveground WTPs \\
\hline $\begin{array}{l}\text { Environmental and } \\
\text { landscaping effects }\end{array}$ & $\begin{array}{l}\text { The upper parts of the WTP structures can be used for } \\
\text { "greenification" and landscaping, but they tend to be } \\
\text { quite scattered. Furthermore, much of their equipment } \\
\text { is exposed. Consequently, the environmental and } \\
\text { landscaping effects of aboveground WTPs are mediocre } \\
\text { at best. }\end{array}$ \\
\hline
\end{tabular}

Integrating aboveground WTPs into natural landscapes and using these sites for other purposes are difficult. As urbanization progresses in China, regional

Social benefits development has been restricted to some extent by wastewater-treatment facilities that were constructed in the past.

Other than the processing rooms and their ancillary

facilities that must be constructed at the surface, the

only other features of an underground WTP that lie on the surface are the equipment hatch, escape hatch, ventilation ports, and odor discharge port. Therefore, large swathes of surface area are still available for greenification, which allows underground WTPs to have excellent environmental and landscaping effects.

Underground WTPs have, to an extent, changed the perception of the general public on WTPs, and they are useful for increasing environmental awareness.

Underground WTPs are viable as "in-city treatment plants."

Underground WTPs are more flexible in terms of where they can be built, and they can be constructed near their serviced areas to reduce delivery and maintenance costs.

Aboveground WTPs are inefficient in terms of land use,

Economic benefits and they exert a negative effect on the usability and market prices of their surrounding lands.

Because the structures of underground WTPs are tightly clustered, they use less land and thus incur lower landpurchase costs. Furthermore, the land above and around an underground WTP still retains a high level of usability and value.

\begin{tabular}{lll}
\hline Construction costs & Low & High \\
\hline Operational costs & Low & High \\
\hline
\end{tabular}

O\&M conditions are far less ideal in underground WTPs, and high levels of ventilation and illumination

Inspection, repair, maintenance, and equipment hoisting in aboveground WTPs are relatively straightforward. are required. Using large machinery for equipment maintenance in underground WTPs is not possible. Hoisting large pieces of equipment requires hoisting holes, and the process depends on the layout of the underground space. Communication between aboveground and underground spaces can be difficult.

Because the working environment is underground, artificial illumination and comprehensive mechanical air supply and exhaust systems are required to maintain these environments, which effectively increase the operational costs.

Because the wastewater-treatment facilities are tightly clustered in an underground WTP, the exhaust ports for deodorization are also clustered. Sealing and collecting odorous gases from the treatment facilities are relatively straightforward, and odorous gases are unlikely to spread to the WTP surroundings in the event of a malfunction in the deodorization system. Because the vast majority of the WTP equipment is located underground, restricting noise emissions is relatively straightforward.

Underground WTPs are required by law to have many fire compartments and a large number of fire escapes that directly lead to the surface. In addition to the firehydrant systems, automatic fire-extinguishing systems must be installed. Care must be taken to prevent flooding. use the interval casting method for the first time to construct a hydraulic structure. Although precedents existed that may have served as references for this project, the suitability of the interval casting method for hydraulic structures remained uncertain. Therefore, finite-element analysis and real-time monitoring were used to ensure the reliability of the interval casting method. According to computational simulations, permanent temperature and stress sensors were 


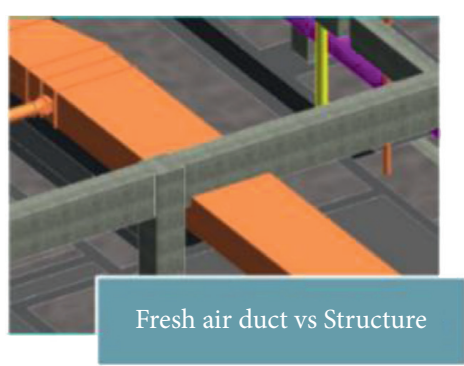

(a)

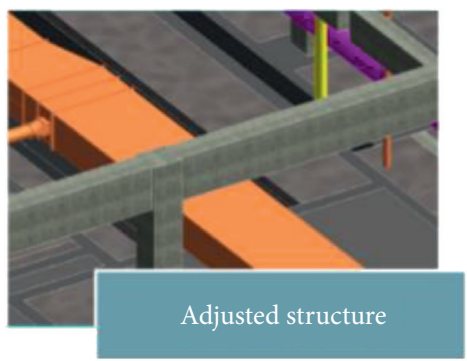

(d)

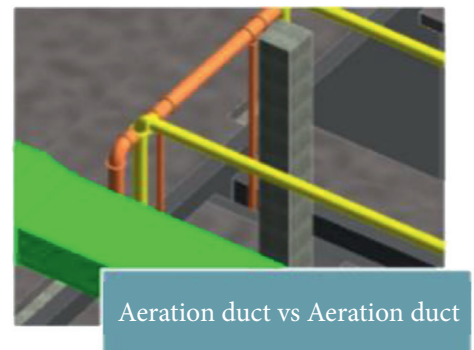

(b)

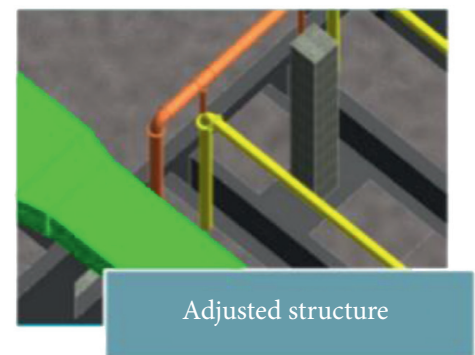

(e)

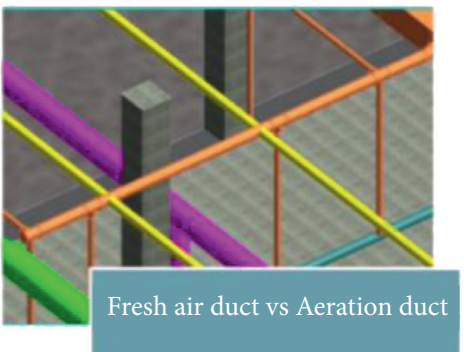

(c)

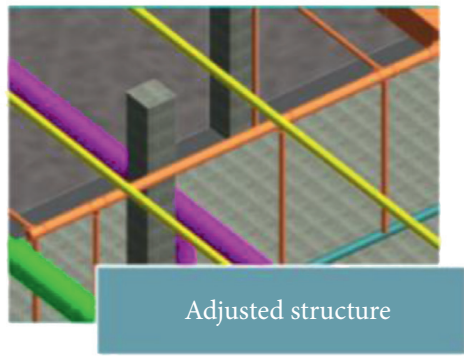

(f)
Fresh air duct Aeration duct Space deodoizing pipe
Channel deodoizing pipe

Sand and scum pipe

FIGURE 2: Interference checking and comparison with adjusted structure.

installed in the HWTP structure to collect stress and temperature data and to monitor structural changes in the concrete. Since the interval casting method was used in this project, we were able to create amenable conditions for the subsequent equipment-installation steps and reduce construction time by 35 days (compared with the delayed pourstrip method), thus allowing the single and combined testing processes to be carried out at an earlier date. This process allowed quicker detection and resolution of structural problems, which helped ensure that HWTP could be commissioned on schedule.

\subsubsection{BIM- and IoT-Based Technologies for O\&M and En- vironmental Monitoring}

(1) BIM- and IoT-Based Monitoring and Analysis of Water Quality and Quantity. A dynamic digital model for WTP water quantity and quality was created to help control the water treatment processes of HWTP and thus facilitate intelligent O\&M management. The intelligent O\&M systems of HWTP allowed monitoring of water levels, flow rates, and water quality at its inputs and outputs and in all relevant areas. On this basis, an improved neural network-based algorithm was created to predict the input water quantity. Firstly, we construct the input data and output data; if the BP neural network model contains $n$ variables, we take the data of $\mathrm{N}$ consecutive time points in the time-series data $\left(x_{\mathrm{t}-\mathrm{n}+1}\right.$, $\left.x_{\mathrm{t}-\mathrm{n}+2}, \cdots, x_{\mathrm{t}}\right)$ as the input and $x_{\mathrm{t}+1}$ as the output, where $x_{\mathrm{t}}$ is the water inflow at $x_{\mathrm{t}}$ time in the time series. The second is to initialize the BP neural network model. The third is model training. Finally, we predict the input water quantity based on the model. The predictions of this algorithm were used to construct a dynamic water-level control model (Figure 5), which helped control the water levels at HWTP under normal conditions and prevented flooding in emergency situations. In addition, the HWTP processes were simulated in BioWin, and the simulation results were then introduced to the BIM system where mathematical models were used to predict the performance of the water treatment process. Therefore, the BIM system could simultaneously analyse the simulated and observed water-quality data (Figure 6) and assist in the regulation of wastewater-treatment processes. Compared with the currently available methods, the proposed method enhanced the predictive and regulation capabilities of the HWTP water treatment processes and helped reduce operational risks. These advantages effectively solve many of the problems associated with the experiencebased approach in controlling the wastewater-treatment processes, which is often slow, risky, and wasteful.

(2) BIM- and IoT-Based Environmental Monitoring and Early Warning System. According to the HWTP features, we developed a method for the integration of multiprotocol dynamic-monitoring systems using BIM, which incorporated the state-of-the-art multiprotocol real-time data-integration techniques. The integration of currently existing automation systems with the BIM system was a challenging process because it involved a multitude of data-transmission protocols, large amounts of data, and stringent demands for responsiveness. To overcome these issues, we developed a method for integrating BIM with the 


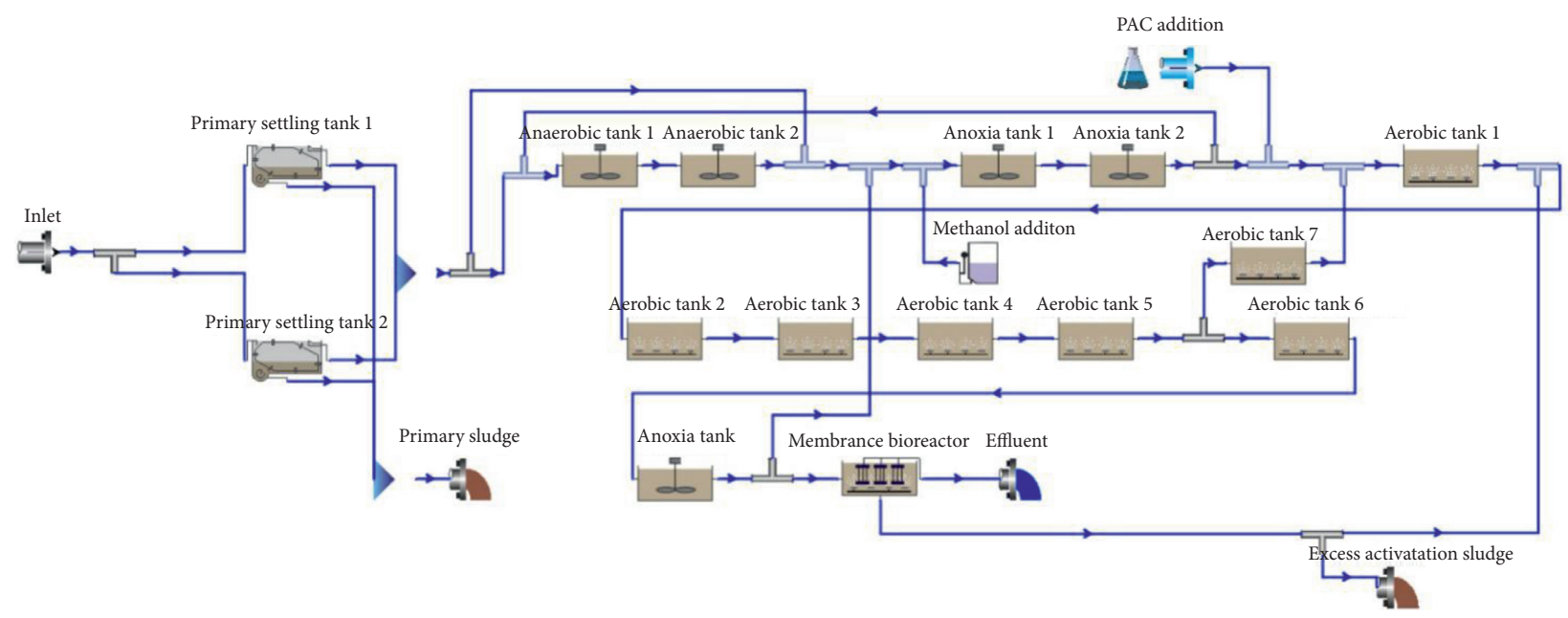

(a)

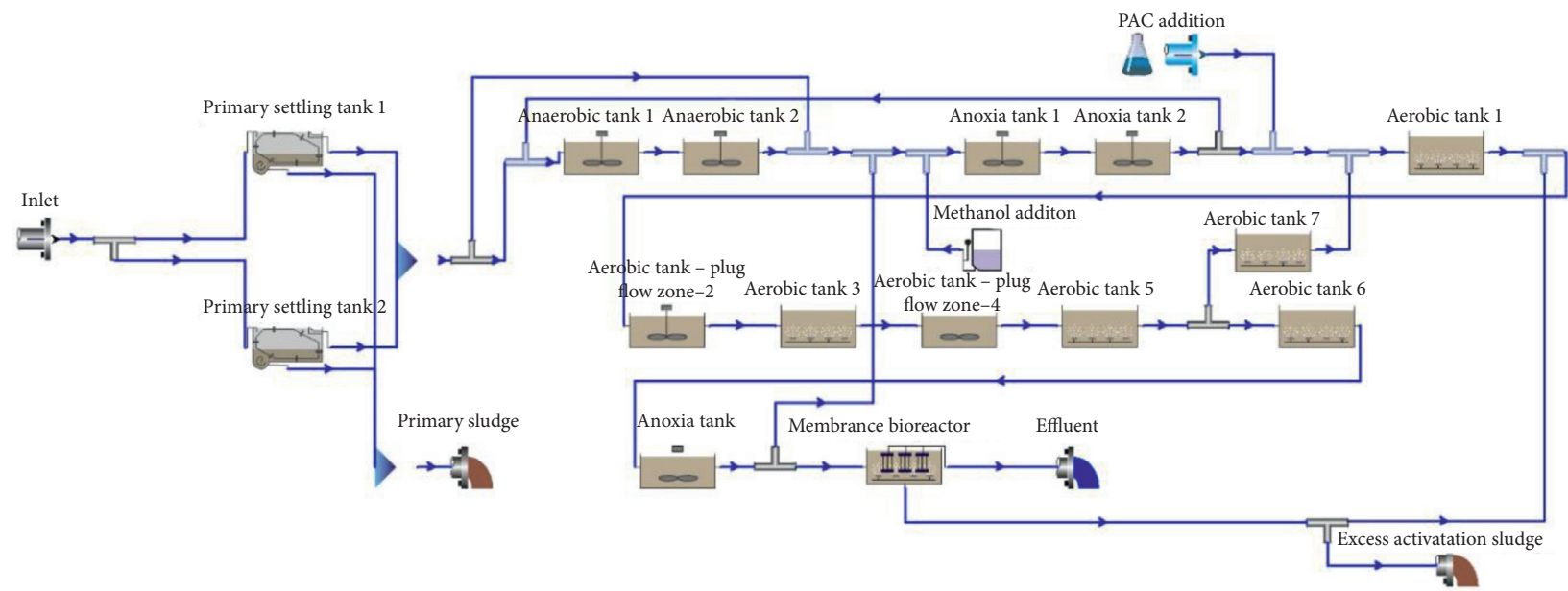

(b)

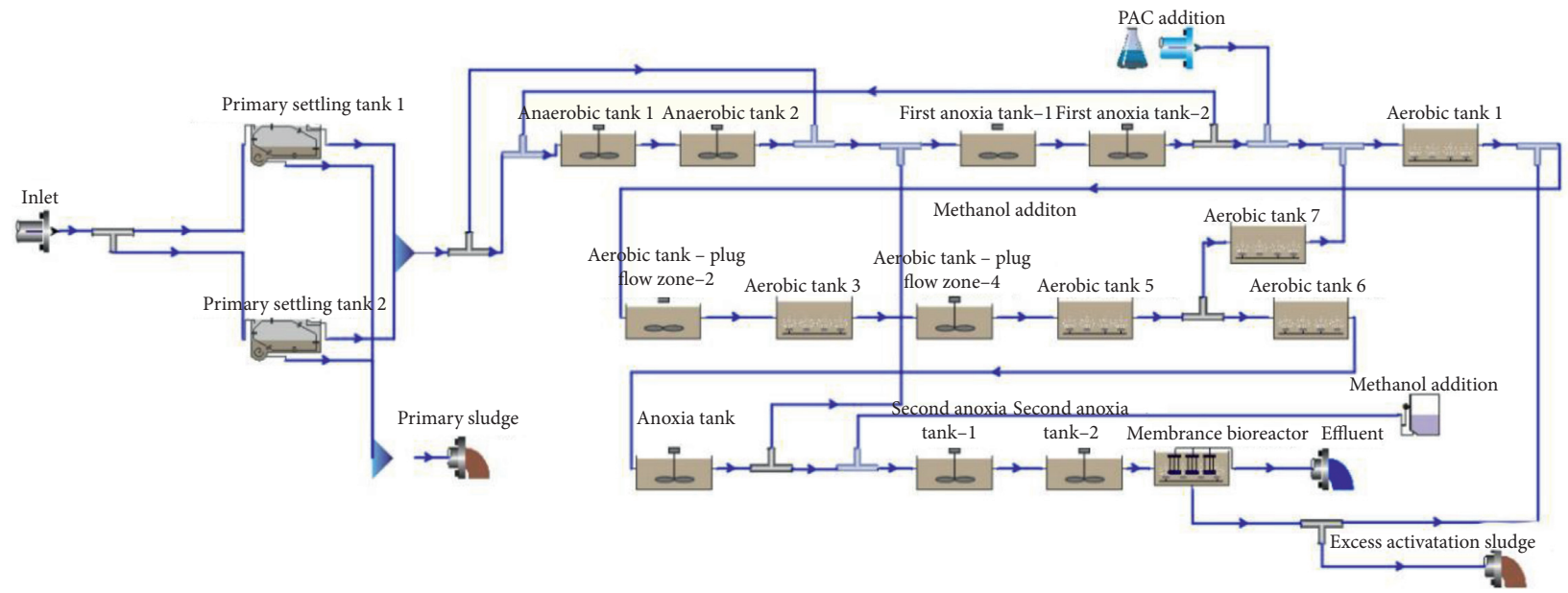

(c)

Figure 3: Simulated process flows: (a) Solution 1; (b) Solution 2; (c) Solution 3. 

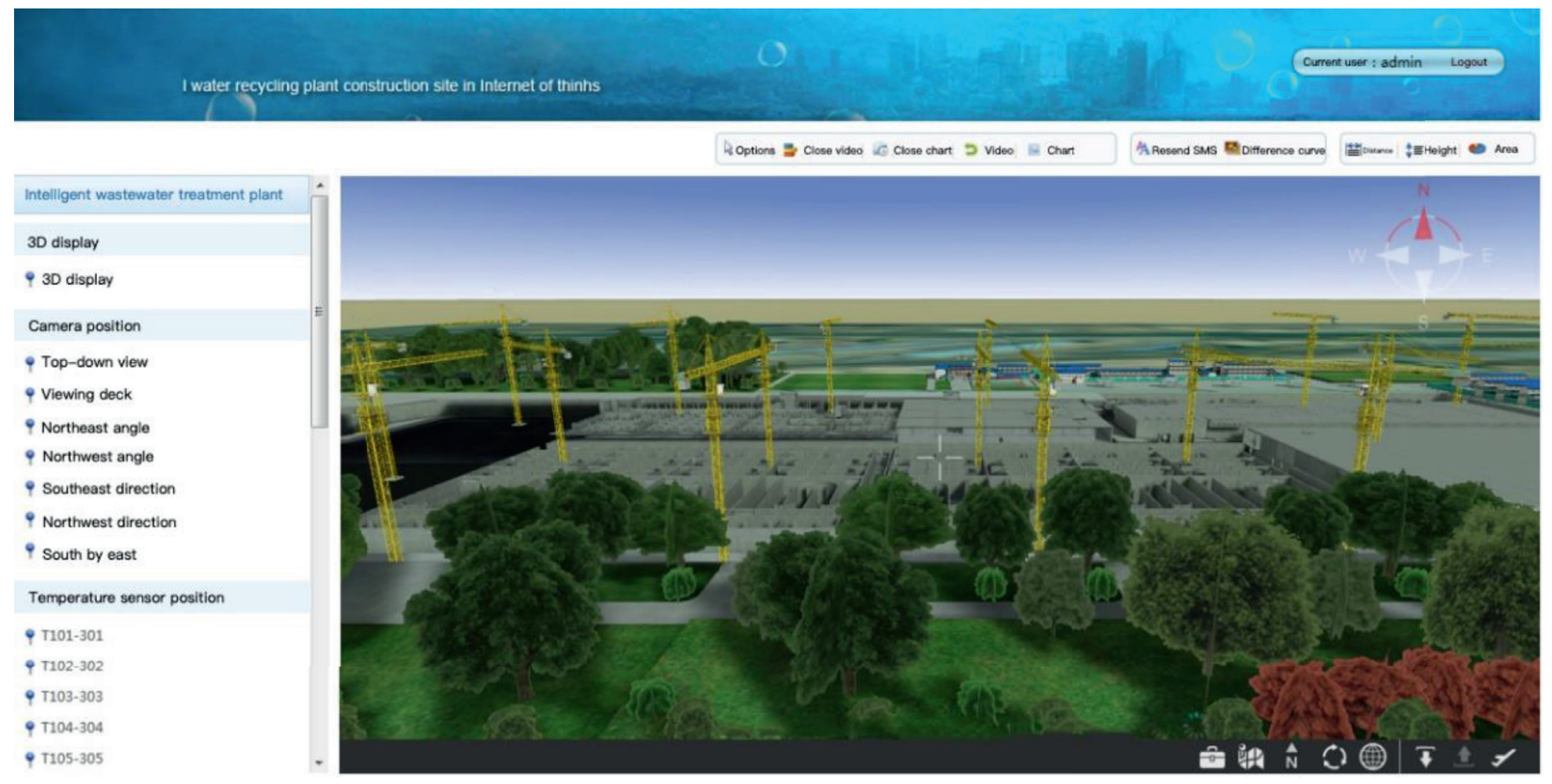

(a)
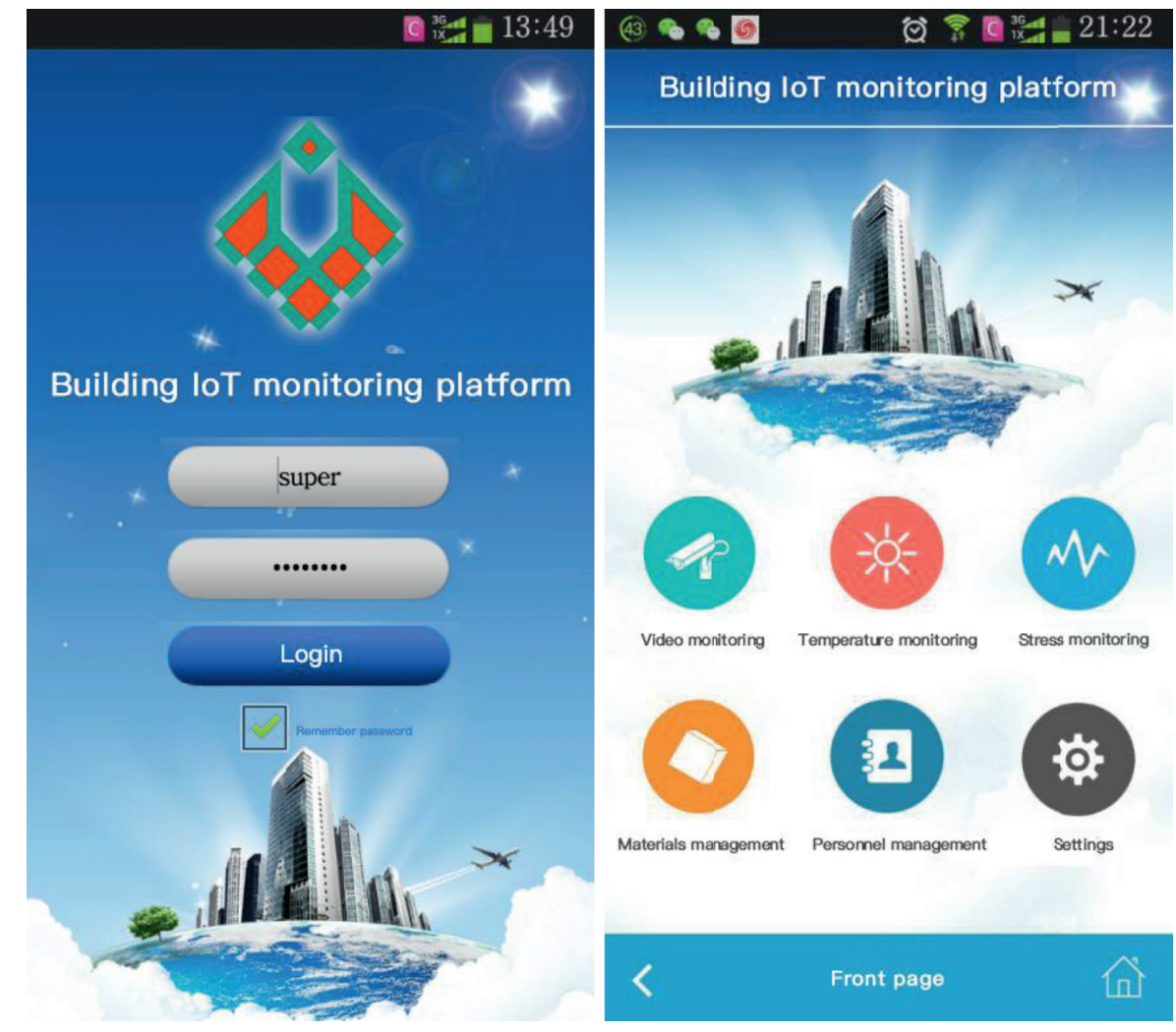

(b)

FIGURE 4: IoT management platform: (a) web terminal; (b) smartphone app mobile terminal. 


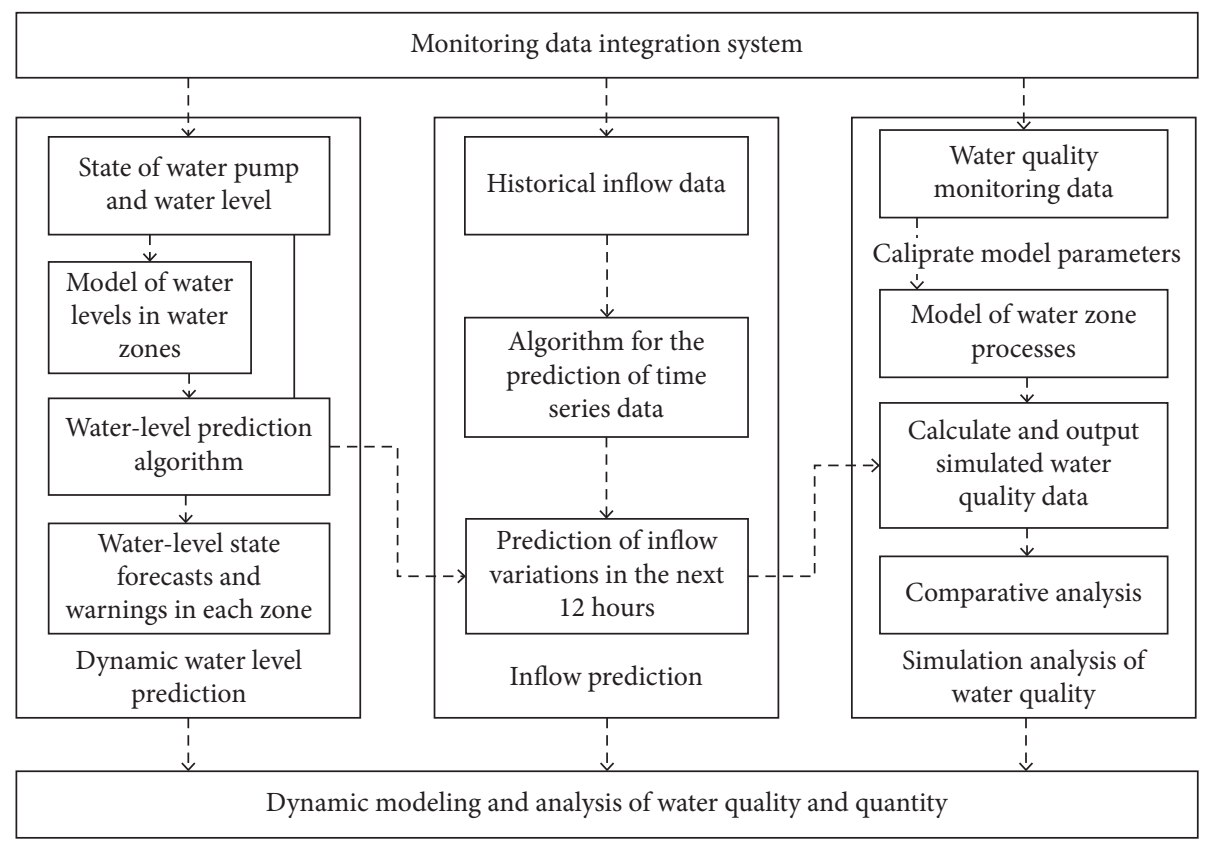

FIGURE 5: Dynamic water-quality and water-quantity modeling and analysis.

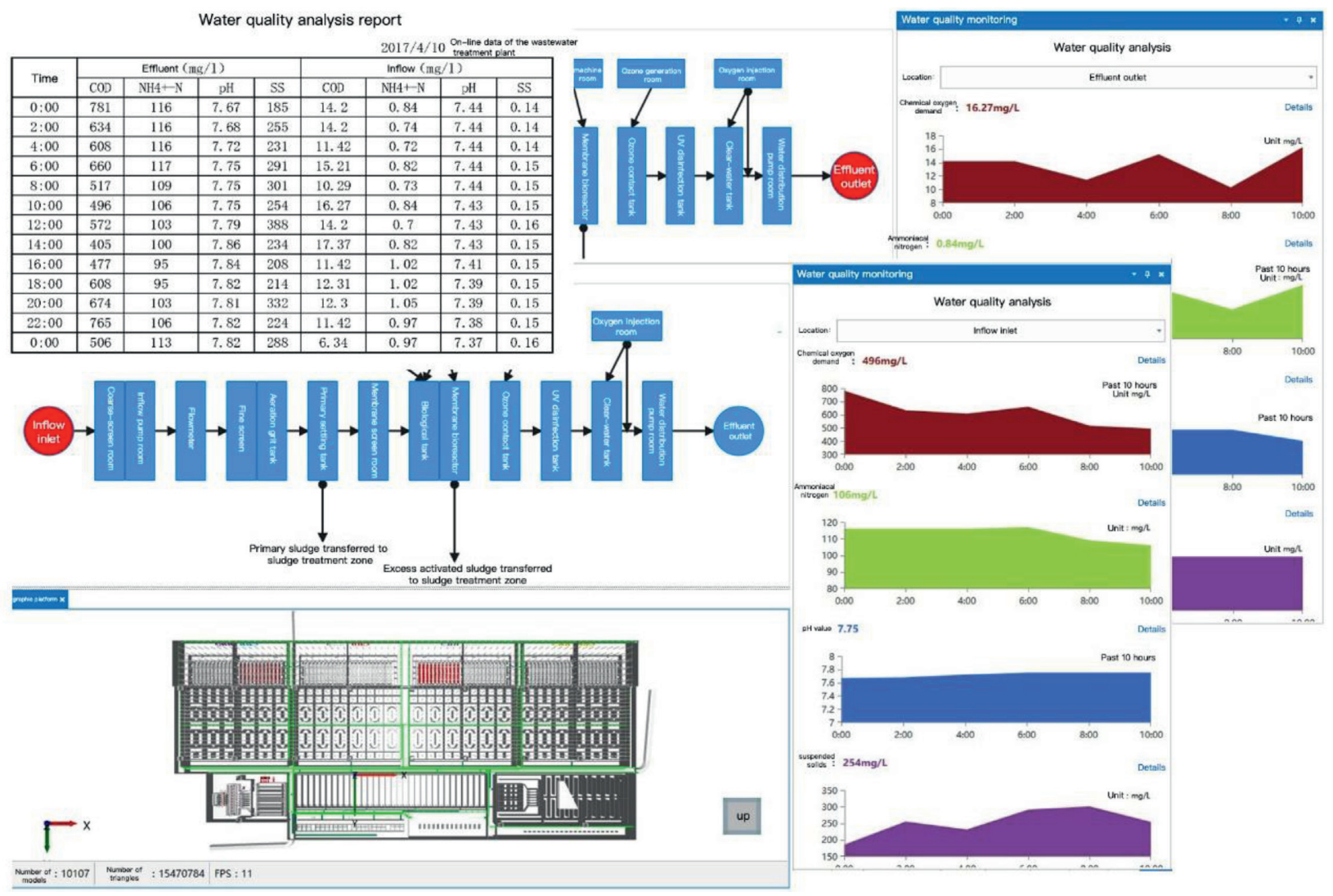

FIGURE 6: Effluent water-quality monitoring and report output.

multiprotocol dynamic-monitoring systems by employing messaging-based distributed architecture, plug-in-based multiprotocol extension, time-series data processing, inmemory database-based real-time data management, time-series database-based historical data management, and RESTful-based data-query services. Using extended attributed sets, the IFC protocol was extended to enable expression of the sensor entity information, sensor features, 


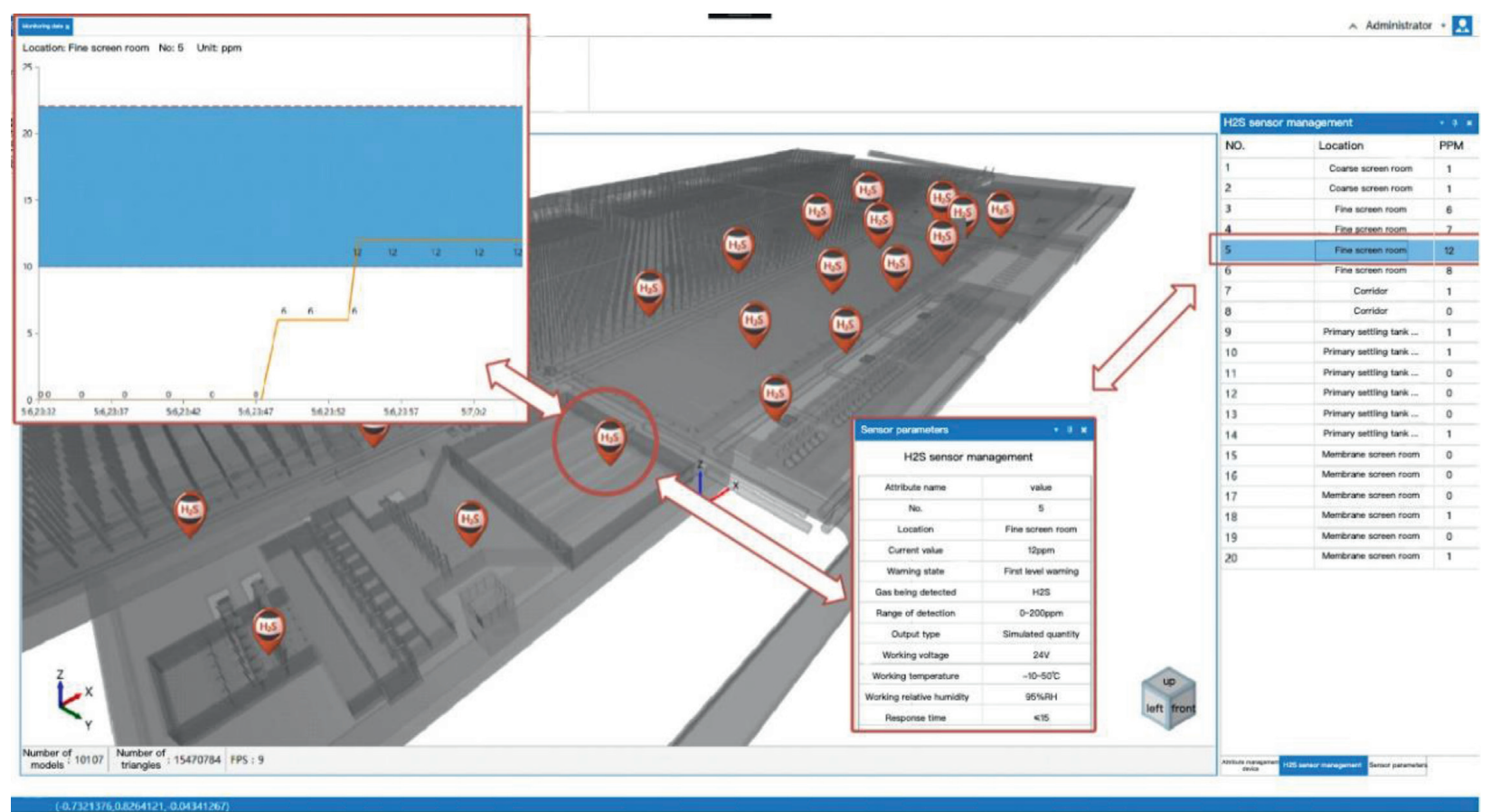

FIgURE 7: Querying the $\mathrm{H}_{2} \mathrm{~S}$ sensor-value trends.

transmission-protocol information, relative positioning data, and historical data to enable storage of monitoring data from the O\&M management processes. In addition, we virtualized the dynamic physical and environmental monitoring data of HWTP and thus developed an O\&M safety management method based on the integration of its physical environment with virtual computing. This method was then supplemented with environmental monitoring and early warning techniques. An early warning and disaster mitigation system for HWTP was thus constructed (Figure 7), which also provided comprehensive analysis and intelligent decisions for O\&M safety. Through the provision of early warning, emergency management, disaster simulations, and disaster guidelines, this system could effectively reduce the probability of disaster occurrence and minimize losses in life and property.

\section{Conclusions and Future Work}

The engineering case for the WTP BIM implementation was based on not only specific features of the construction project but also implicit assumptions about the nature of the industry and its work. In the key stages of 3D modeling, operation monitoring, as well as design options comparison and construction simulation, this project makes full use of BIM technology for visual expression, performance analysis, digital simulation, and high-efficiency information transfer. Under the framework of smart engineering design, the project quality, construction management level, and later operational efficiency have been significantly improved. During the design phase, the BIM model was used to perform specialized simulations of the key nodes to help optimize its design and the BioWin simulator was used to simulate and optimize the WTP processes and provide technical support for the O\&M processes. During the construction phase, a BIM- and IoT-based construction platform was established which effectively improved the ability of fine management and control of the project. During the O\&M phase, the WTP realized scientific management and intelligent O\&M based on BIM and IoT technology, such as automatic monitoring and analysis of water quality and quantity and environment. Therefore, the project realized the transmission and sharing of data in the whole life cycle and maximized the cooperation of all participants, which played an important role in improving production efficiency, saving cost, and shortening construction period. In the end, the project became a model of a smart underground wastewater-treatment plant.

In addition to the papers presented in the literature review, this paper is one of the first developments of BIM applied in the WTP construction and O\&M. Considering the evolution of the IoT and development of the digital twin and artificial intelligence, we believe that the construction of intelligence WTP should be further developed in the following two aspects.

First, future WTP developments should incorporate deep learning. Currently, the combination of advanced software and hardware has enabled partial automation and "intelligentization" of the WTP construction and O\&M. However, a large amount of human input is still needed, and we have yet to solve the root causes of the issues associated with the experience-based approaches for the control of wastewater-treatment processes, which are often slow, risky, and wasteful. As we continue to accumulate data from the WTP operation, artificial-intelligence techniques such as deep learning will be needed to create predictive models for 
WTP operations, which will greatly increase the accuracy of these predictive models.

Second, intelligent control systems should be developed for WTP operations. Although some works have been done on the monitoring and prediction of input water quality and operation control at HWTP, human intervention remains necessary for sewage treatment. Therefore, in the future, we should aim to create a cyber physical system that will enable systematic and intelligent control of wastewater-treatment systems.

\section{Data Availability}

The data used to support the findings of the study are included in the article.

\section{Conflicts of Interest}

The authors declare that they have no conflicts of interest.

\section{Acknowledgments}

The authors would like to acknowledge the Consulting research project of Chinese Academy of Engineering and the Beijing Science and Technology Project for financially supporting this work under contract number 2016-XZ-14 and Z151100002115054 and thank the contractor and project staff who participated.

\section{References}

[1] IEA, The 2019 Global Status Report for Buildings and Construction, United Nations Environment Programme, Nairobi, Kenya, 2019.

[2] P. J. Davies, S. Emmitt, and S. K. Firth, "Delivering improved initial embodied energy efficiency during construction," Sustainable Cities and Society, vol. 14, pp. 267-279, 2015.

[3] I. Z. Bribian, A. V. Capilla, and A. A. Uson, "Life cycle assessment of building materials: comparative analysis of energy and environmental impacts and evaluation of the eco-efficiency improvement potential," Building and Environment, vol. 46, no. 5, pp. 1133-1140, 2011.

[4] J. P. Xu, Y. W. Deng, Y. Shi et al., "A bi-level optimization approach for sustainable development and carbon emissions reduction towards construction materials industry: a case study from China," Sustainable Cities and Society, vol. 53, pp. 1-15, 2020.

[5] M. Honic, I. Kovacic, and H. Rechberger, "Improving the recycling potential of buildings through Material Passports (MP): an Austrian case study," Journal of Cleaner Production, vol. 217, pp. 787-797, 2019.

[6] N. Wang, "The role of the construction industry in China's sustainable urban development," Habitat International, vol. 44, pp. 442-450, 2014.

[7] U. Berardi, "Clarifying the new interpretations of the concept of sustainable building," Sustainable Cities and Society, vol. 8, no. Complete, pp. 72-78, 2013.

[8] R. M. Pulselli, E. Simoncini, F. M. Pulselli, and S. Bastianoni, "Emergy analysis of building manufacturing, maintenance and use: em-building indices to evaluate housing sustainability," Energy and Buildings, vol. 39, no. 5, pp. 620-628, 2007.
[9] UNEP, Sustainable Building and Construction: Facts and Figures, United Nation Environment Programme: Industry And Environment, Nairobi, Kenya, pp. 5-8, 2003, Online] Available from http://www.uneptie.org/media/review/ vol26no2-3/005-098.pdf (Accessed: 19 March 2017.

[10] Y. Xing, N. Hewitt, and P. Griffiths, "Zero carbon buildings refurbishment--A Hierarchical pathway," Renewable and Sustainable Energy Reviews, vol. 15, no. 6, pp. 3229-3236, 2011.

[11] G. Ali, T. John, G. Amirhosein et al., "Building Information Modelling (BIM) uptake: clear benefits, understanding its implementation, risks and challenges," Renewable \& Sustainable Energy Reviews, vol. 76, pp. 1046-1053, 2017.

[12] M. Oraee, M. R. Hosseini, E. Papadonikolaki, R. Palliyaguru, and M. Arashpour, "Collaboration in BIM-based construction networks: a bibliometric-qualitative literature review," International Journal of Project Management, vol. 35, no. 7, pp. 1288-1301, 2017.

[13] I. Othman, Y. Y. Al-Ashmori, Y. Rahmawati et al., "The level of building information modelling (BIM) implementation in Malaysia," Ain Shams Engineering Journal, vol. 12, pp. 455463, 2020.

[14] B. Ilhan and H. Yaman, "Meta-analysis of building information modeling literature in construction," International Journal of Engineering and Innovative Technology, vol. 3, no. 4, pp. 373-379, 2013.

[15] N. Bui, C. Merschbrock, and B. E. Munkvold, "A review of building information modelling for construction in developing countries," Procedia Engineering, vol. 164, pp. 487-494, 2016.

[16] D. Migilinskas, V. Popov, V. Juocevicius, and L. Ustinovichius, "The benefits, obstacles and problems of practical bim implementation," Procedia Engineering, vol. 57, pp. 767-774, 2013.

[17] Y. Y. Al-Ashmori, I. B. Othman, Y. Rahmawati et al., "BIM benefits and its influence on the BIM implementation in Malaysia," Ain Shams Engineering Journal, vol. 11, pp. 10131019, 2020.

[18] S. Azhar, M. Khalfan, and T. Maqsood, "Building information modeling (BIM): now and beyonds," Australasian Journal of Construction Economics and Building, vol. 12, no. 4, pp. 15-28, 2012.

[19] J. L. Li, Key Technologies and Engineering Applications of Smart construction, China Construction Industry Press, Beijing, China, 2017, in Chinese. 